\title{
The Application of Bamboo Network Reinforcement Technology on Hydraulic Fill Soft-Soil Foundation Treatment
}

\author{
Man Yuan, Jihui Ding*, Yanliang Cao \\ College of Civil Engineering, Hebei University, Baoding, China \\ Email: ${ }^{*}$ dingjihui@126.com
}

Received 4 March 2014; revised 7 April 2014; accepted 16 April 2014

Copyright (C) 2014 by authors and Scientific Research Publishing Inc.

This work is licensed under the Creative Commons Attribution International License (CC BY). http://creativecommons.org/licenses/by/4.0/

\section{(c) (i) Open Access}

\begin{abstract}
To make a large area of dredger fill silt surface layer form working face and subsequent construction problems, the project conducts the bamboo network reinforcement in the silt surface layer. It makes the surface layer bearing capacity to meet the construction requirement of deep processing. Based on Shantou Municipal Road Embankment Treatment Engineering and the project, the bamboo network reinforcement technology to reinforce the dredger fill super soft soil surface layer is used. The results show that the bearing capacity of hydraulic fill super soft soil surface layer is $32.6 \mathrm{kPa}$ after 3 months treatment. The surface layer bearing capacity after 3 months treatment improved $323 \%$ than the early treatment and increased $695 \%$ than no processing. The results indicate that the reinforcement effect is outstanding and provide the basis for drafting the dredger fill super soft soil surface layer treatment plan.
\end{abstract}

\section{Keywords}

Hydraulic Fill Super Soft Foundation, Surface Layer Silt, Bamboo Network, Capacity Calculation, Cone Penetration Test

\section{Introduction}

With development of the hydraulic fill technology, the land reclamation will become the main means, which solves the land need of coastal cities. The land reclamation site has the inhomogeneity in the horizontal direction and the vertical direction. The water content is generally $80 \%-150 \%$ or higher. The site is flowing mud state

\footnotetext{
*Corresponding author.
}

How to cite this paper: Yuan, M., Ding, J.H. and Cao, Y.L. (2014) The Application of Bamboo Network Reinforcement Technology on Hydraulic Fill Soft-Soil Foundation Treatment. World Journal of Engineering and Technology, 2, 68-72. 
even though floating sludge and its carrying capacity are very small. Therefore, the surface layer must be reinforced.

The common pretreatment technologies of surface layer silt and mud flows have multi-layer geogrid + geotextile + sand cushion technology, the pretreatment technology of the wattle and bamboo sheathings, no sand vacuum preloading and so on. The surface pretreatment bamboo network technology [1]-[4] is a surface layer pretreatment technology that is based on the raft technology, which inserts the vertical bamboo in the silt and makes the bamboo network into the frame bamboo network structure. Because this technique makes the bamboo raft become three-dimensional framework, the bamboo network tends to stabilize in the plane. The surface pretreatment technology has a strong practical significance for the flowing mud and fluid mud site in which the water content is greater than $\mathbf{1 0 0 \%}$. The paper consults the Shantou Municipal Road Embankment Treatment Engineering and uses the bamboo network surface layer reinforcement technology to reinforce the dredger fill super soft soil surface layer.

\section{Project Overview}

The project is in the hydraulic fill area of Shantou City, Guangdong Province. According to the survey report, the hydraulic fill area is a large area hydraulic fill backwater silt area. There is $3-6 \mathrm{~m}$ very soft blow-fill silt in the surface layer. It is saturated and flow plastic. Because the hydraulic sorting, the silt layer soil particles that are mainly the clay and the colloidal particles is very small. The particles don't connect to the soil skeleton structure of certain intensity. The silt layer is the flocculent flowing mud and the fluid mud. The bearing capacity is very low. The following layers are medium-fine sand, sludge, medium coarse sand and fine sand, etc. They have a certain bearing capacity and are beyond the scope of surface layer treatment.

Geotechnical conditions are as follows:

(1) 4 layer silt: flow-flow plastic, grey black, containing particle, high water content , the thickness is $3.0-6.0$ $\mathrm{m}$, the average thickness is $3.88 \mathrm{~m}, q_{c}=0-0.28 \mathrm{MPa}, f_{a k}<5.0 \mathrm{kPa}$, the new super soft soil.

$1_{2}$ layer medium-fine sand: saturated, loose, medium sand is main, containing coarse sand, the thickness is 0.4 - $5.0 \mathrm{~m}$, the average thickness is $2.49 \mathrm{~m}$.

(2) 1 layer silt: grey, flow plastic, saturated, containing a small amount of silty sand, the thickness is $3.4-5.6 \mathrm{~m}$, the average thickness is $4.27 \mathrm{~m}, w=59 \%, e=0.619, I_{p}=9.2, E_{S 1-2}=1.999 \mathrm{MPa}, P_{c}=0.8 \mathrm{kPa}, \mathrm{t} C_{c}=0.476, f_{a k}=$ $50 \mathrm{kPa}$, high water content, high compression native soft soil.

(3) 1 layer medium coarse sand: saturated, loose, local containing silt, the thickness is $1-2.6 \mathrm{~m}$, the average thickness is $1.7 \mathrm{~m}$, the SPT count $N$ is 5.9 , medium liquefaction.

(3) 3 layer fine sand: saturated, loose, containing a small amount of clay, the thickness is 0.7 - 1.8 m, the average thickness is $1.13 \mathrm{~m}$, the SPT count $N$ is 5.5, medium liquefaction.

(4) 1 layer silt-mucky soil: clay, grey, saturated, flow plastic, more thin layer fine or coarse sand, the thickness is $1.1-4.5 \mathrm{~m}$, the average thickness is $2.72 \mathrm{~m}, w=40.8 \%, e=1.113, E_{S 1-2}=2.166 \mathrm{MPa}, P_{c}=: 45.9 \mathrm{MPa}, C_{c}=$ $0.369 \mathrm{kPa}, f_{a k}=80 \mathrm{kPa}$, high compressibility soft soil.

(5) ${ }_{2}$ layer clay-silty clay: slightly wet, soft-plastic, local mixing more fine sand, 13.9 - $20.5 \mathrm{~m}$, average $17.38 \mathrm{~m}$, $E_{S 1-2}:=7.1 \mathrm{MPa}, P_{c}=281.4 \mathrm{kPa}, f_{a k}=130 \mathrm{kPa}$.

In which, $q_{c}$ is the end Resistance, $N$ is the SPT Number, $w$ is water content, $e$ is the void ratio, $I_{p}$ is the plasticity index, $E_{S 1-2}$ is the compression modulus, $P_{c}$ is the pre-consolidation pressure, $C_{c}$ is the Compression Index, $f_{a k}$ is the characteristic value of bearing capacity.

\section{Surface Layer Bamboo Network Reinforcement Technology}

The main technological processes of surface layer bamboo network reinforcement technology on hydraulic fill ultra-soft Foundation are as follows: (1) Laying a layer of woven cloth in the silt surface. The role of woven cloth mainly forms a working face in silt surface; (2) Laying the vertical bamboo network. The bamboo network spacing is same. The thick section of bamboo laps the finer part in the bamboo network. The lap length is greater than $1 \mathrm{~m}$. Binding lap section with wire. The direction of bind iron wire must be opposite; (3) First, laying a layer of woven cloth on the bamboo network. Later, laying sand cushion layer on the bamboo network. Laying sand cushion needs to use small devices. After laying a path in the middle area, paving the both sides. At the same time, it is necessary to prevent the uplift of bamboo network edge. After the above three steps, the dredger fill area forms the subsequent construction working surface. 


\section{Surface Layer Bearing Capacity Calculation}

\subsection{Surface Layer Bearing Capacity without Reinforcement}

The ultra soft soil surface layer bearing capacity verify uses Terzaghi’s Ultimate Bearing Capacity Formula [5]:

$$
q=\frac{1}{2} \gamma B N_{r}+q N_{q}+c N_{c}
$$

which, $q$ is the ultimate bearing capacity, $\mathrm{kPa} ; N_{r}, N_{q}$ and $N_{c}$ are the Coefficients of the Terzaghi's bearing capacity. $\gamma$ is the soil layer weight per unit valume, $B$ is the upper load width, $c$ is the cohesive force of soil layer, $q$ is the upper load.

When $\varphi=0^{\circ}$ and $\mathrm{q}=0$, Formula (1) simplifies to

$$
q=c N_{c}
$$

Based on Formula (2), the allowable bearing capacity of surface layer is

$$
q_{a}=\frac{c N_{c}}{F_{s}}
$$

Where, $F_{s}$ is Security Coefficient.

Take $c=1.45 \mathrm{kPa}, N_{c}=5.71, F_{s}=2.0$, and Substitution Formula (3), and then the foundation surface layer bearing capacity $q_{a}=4.1 \mathrm{kPa}$.

\subsection{Equipment Grounding Stress}

The project needs to cover soil and insert the plastic drainage plate before the deep processing. Therefore, it is necessary to calculate the equipment grounding stress. Calculating diagram is shown in Figure 1. When the allowable bearing capacity of foundation surface layer is less than or equal to the equipment grounding stress ( $q_{a} \leq \sigma$ ), the foundation needs strengthening. Otherwise, if $q_{a}>\sigma$, it is not needed.

The equipment grounding stress calculates by the stress diffusion theory [6].

$$
\sigma=\frac{W(1+\alpha)}{2(B+2 d \tan \theta)(L+2 d \tan \theta)}+\gamma_{t} d
$$

Which, $\sigma$ is the equipment grounding stress, $\mathrm{kPa} ; W$ is the equipment weight, $\mathrm{kN} ; B$ is the track width, $\mathrm{m} ; L$ is the track length, $\mathrm{m} ; d$ is the overburden thickness, $\mathrm{m} ; \gamma_{t}$ is the soil weight per unit volume, $\mathrm{kN} / \mathrm{m}^{3} ; \alpha$ is the impact coefficient of covering soil on Equipment ascertains by Table 1, $\theta$ is stress diffusion angle, and takes $30^{\circ}[6]$.

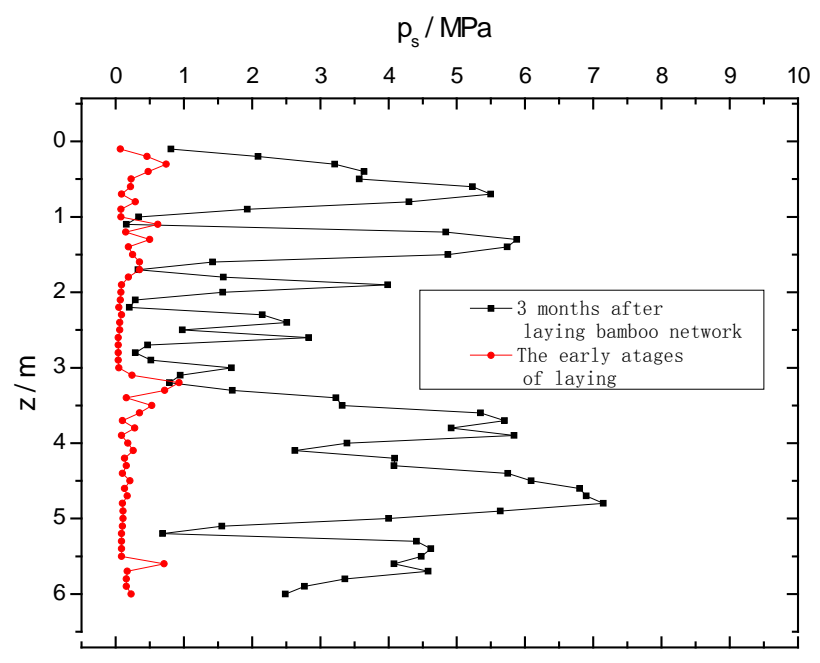

Figure 1. The single bridge static sounding curve. 
Table 1. The impact coefficient of overburden on equipment.

\begin{tabular}{cc}
\hline Covering Soil Thickness/cm & $\begin{array}{c}\text { Impact Coefficient Of Covering } \\
\text { Soil on equipment }(\alpha)\end{array}$ \\
\hline$<30$ & 0.3 \\
$30-60$ & 0.2 \\
$60-90$ & 0.1 \\
$>90$ & 0 \\
\hline
\end{tabular}

The equipment (802 K Bulldozer) grounding stress $(\sigma)$ of construction engineering is calculated by formula (4). When the casing soil are $0.7 \mathrm{~m}, 0.8 \mathrm{~m}$ and $1.0 \mathrm{~m}$, the equipment grounding stress are $15.3 \mathrm{kPa}, 17.2 \mathrm{kPa}$, $21.0 \mathrm{kPa}$. These are greater than the foundation surface layer bearing capacity. Therefore, it is necessary to treat the foundation surface layer.

\subsection{Foundation Surface Layer Bearing Capacity after Strengthening}

The foundation surface layer bearing capacity including strengthening materials and overburden is calculated by Yamanouchi Formula [6].

$$
\begin{aligned}
& q_{a}=\frac{1}{F_{s}}\left(1+\frac{d}{B}\right)\left(5.3 c+\frac{2 T_{a}}{B} \sin \theta\right) \\
& T_{a}=\frac{\sigma \pi\left(R^{2}-r^{2}\right)}{F_{T}}
\end{aligned}
$$

Which, $F_{s}$ is the short-term safety coefficient (2.0); $d$ is the overburden thickness, $\mathrm{m}$; $B$ is the track width, m; $c$ is the cohesive force, $\mathrm{kPa}$; Ta is the allowable reinforcement materials tension, $\mathrm{kN} / \mathrm{m}, T_{a}$ include bamboo network and woven. Because the strength of woven is low, it can be ignored; $\theta$ is the angle between the horizontal plane and the reinforcement materials $\left(20^{\circ}\right) ; \sigma$ is the bamboo tensile strength $\left(2000 \mathrm{~kg} / \mathrm{cm}^{2}\right) ; R$ is the external diameter $(5 \mathrm{~cm}) ; r$ is the internal diameter $(4 \mathrm{~cm}) ; F_{T}$ is the bamboo network safety factor (2.0).

\subsection{Bamboo Network Laying Scheme}

The bamboo network laying scheme is established by load test. The relationship between the allowable carrying capacity before and after reinforced [6]:

$$
B C R=\frac{q_{a}}{q_{0}}=4.4909(H / S)^{0.6153}
$$

which, $q_{a}$ is the allowable carrying capacity before reinforced, $\mathrm{kPa} ; q_{0}$ is allowable bearing capacity of original foundation, $\mathrm{kPa} ; H$ is the overburden thickness, $\mathrm{m}$; $S$ is the bamboo network spacing, $\mathrm{m}$.

The bearing capacity and equipment grounding stress is showed in Table 2 in different the bamboo network spacing and the covering soil thickness.

According to the construction and economic conditions, the project chooses $0.5 \mathrm{~m}$ spacing to lay bamboo network and $1.0 \mathrm{~m}$ sand cushion. On the basis of (7) formula, BCR equal 6.8. The allowable bearing capacity is $28.2 \mathrm{kPa}$ after reinforced. The calculation results and load test results are basically the same. It meets the requirement.

\section{Cone Penetration Test Data}

The engineering uses $0.5 \mathrm{~m}$ spacing bamboo network and $0.5 \mathrm{~m}$ sand cushion to treat the silt surface layer. The single bridge static sounding curve is showed in Figure 1. The average specific penetration resistances are 0.2 $\mathrm{MPa}$ and $3.24 \mathrm{MPa}$ at two time points. The allowable bearing capacity is calculated by Cone Penetration Test Bearing Capacity Empirical Formula [7].

$$
q_{a}=0.58 \sqrt{P_{s}}-0.46
$$


Table 2. The calculation results of bearing capacity and equipment grounding stress.

\begin{tabular}{cccccc}
\hline \multirow{2}{*}{$\begin{array}{c}\text { Bamboo Network } \\
\text { Spacing/m }\end{array}$} & $\begin{array}{c}\text { Overburden } \\
\text { Thickness/m }\end{array}$ & $\begin{array}{c}\text { Equipment Grounding } \\
\text { Stress/kPa }\end{array}$ & \multicolumn{2}{c}{ Allowable Bearing Capacity/kPa } & Evaluation \\
\cline { 4 - 5 } & 0.7 & 15.3 & 56.1 & 29.7 & OK \\
0.4 & 0.7 & 15.3 & 45.8 & 26.5 & OK \\
0.5 & 0.8 & 17.2 & 46.5 & 28.3 & OK \\
0.5 & 1.0 & 21.0 & 48.1 & 30.1 & OK \\
\hline
\end{tabular}

which, $P_{s}$ is the specific penetration resistance, $\mathrm{kPa} ; q_{a}$ is the allowable carrying capacity of original foundation, $\mathrm{kPa}$.

The surface layer bearing capacity is average $7.7 \mathrm{kPa}$ in early laying by (8). The surface layer bearing capacity is average $32.6 \mathrm{kPa}$ after 3 months. These calculation results compare with the load test results and the formula (7) calculation results. The results show that the three are basically the same. The surface layer bearing capacity after 3 months improved 323\% than the early treatment and improved 695\% than no processing by the above calculated values. The results show that the surface layer bearing capacity is outstanding.

\section{Conclusions}

Based on the Shantou Municipal Road Embankment Treatment Engineering, the project chooses $0.5 \mathrm{~m}$ spacing to lay bamboo network and $1.0 \mathrm{~m}$ sand cushion to treat silt surface layer. The results show that the super-soft soil carrying capacity is $32.6 \mathrm{kPa}$ after 3 months. The surface layer bearing capacity improves $323 \%$ after 3 months treatment than early treatment. It improves 695\% after 3 months treatment than no treatment.

The vertical bearing capacity is mainly considered and the lateral slip is ignored, because the bamboo network lays in the silt surface, overburden will inevitably result in the silt outside, the uplift of bamboo network edge and the slip of bamboo network. The bamboo network edge needs to be reinforced. The concrete reinforcement design requires further study.

\section{References}

[1] Dong, Z.L., Zhang, G.X., Mo, H.H., et al. (2008) The Rapid Strengthening Method and Packaged Technology of the Ultra Soft Soil Shallow Surface. Chinese Patent No. 200810026168.

[2] Dong, Z.L., Zheng, X.L. and Qi, G.Q. (2006) The Soft Function Pre-Pressure Drainage Consolidation Method without Sand Cushion. Chinese Patent No. 2006100339374.

[3] Dong, Z.L., Zhang, G.X., Zheng, X.L. et al. (2008) An Ultra Soft Soil Shallow Rapid Reinforcement System. Chinese Patent No. 2007200503398.

[4] Chen, C.N. and Xu, J.M. (2007) The Application of Bamboo Network in Super Soft Foundation Engineering Silt Surface Layer Treatment. Port \& Waterway Engineering, 10, 75-77.

[5] Li, J.P., Liang, F.Y. and Zhao, C.F. (2008) Soil Mechanics. Higher Education Press, Beijing, 247-248.

[6] Shen, Z.J. and Liang, J.S. (2009) The Construction Method of Using the Bamboo Network to Process Soft Foundation Surface Layer. Chinese Patent No. 2008101672655.

[7] Shi, M.S., Zhang, Z.Y. and Wei, J. (1994) Determining Foundation Bearing Capacity Theory Formula by the Cone Penetration Test. Journal of Zhengzhou Institute of TECH, 15, 36-37. 